\title{
Managing conflicts of interest in the development of health guidelines
}

\author{
Gregory Traversy MSc, Lianne Barnieh MSc PhD, Elie A. Akl MD PhD, G. Michael Allan MD, Melissa Brouwers PhD, \\ Isabelle Ganache PhD, Quinn Grundy RN PhD, Gordon H. Guyatt MD MSc, Diane Kelsall MD MEd, Gillian Leng CBE, \\ Ainsley Moore MD MSc, Navindra Persaud MD MSc, Holger J. Schünemann MD PhD, Sharon Straus MD MSc, \\ Brett D. Thombs PhD, Rachel Rodin MD, Marcello Tonelli MD SM
}

Cite as: CMAJ 2021 January 11;193:E49-54. doi: 10.1503/cmaj.200651

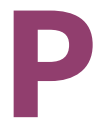

ublic awareness regarding the importance of disclosing and managing conflicts of interest (COIs) during the development of clinical practice and public health guidelines is growing, owing to recent high-profile news stories within and outside Canada. ${ }^{1-9}$ Despite the existence of guidance on the development of high-quality guidelines, ${ }^{10}$ and although a broad range of standards, principles and policies have been developed for mitigating the effects of COls on guidelines, ${ }^{11-19}$ specific approaches vary widely among guideline producers. Some organizations take a stricter approach - excluding participants with any $\mathrm{COI}$ from guideline development - while others have no publicly available policies to indicate how COls are managed. ${ }^{20,21}$

We discuss best practices for managing COIs in the development of health guidelines, drawing on the approach articulated by the Guidelines International Network (GIN), ${ }_{12}^{12}$ as well as on an environmental scan of the Canadian and international landscape, interviews with Canadian guideline developers and feedback received from various stakeholders through a Canadian Institutes of Health Research (CIHR) Best Brains Exchange ${ }^{22}$ (Appendix 1, available at www.cmaj. ca/lookup/doi/10.1503/cmaj.200651/tab-related-content). We also provide an online toolkit to support the implementation of robust processes for COI management (https://wiki.gccollab.ca/PHAC_ Conflict_of_Interest_Toolkit_for_Guideline_Development).

\section{Why is it important to carefully manage COIs in the development of guidelines?}

Guidelines are "systematically developed statements to assist practitioner and patient decisions about appropriate health care for specific clinical circumstances." ${ }^{11}$ When developed using transparent and rigorous methods, guidelines can help practitioners to deliver care that is consistent with the best available evidence. Guideline development requires judgments about which evidence to include; the certainty of that evidence; the balance of benefits, harms and other desirable and undesirable consequences; and the strength of recommendations.

Conflicts of interest represent situations in which the judgment of an individual may be unduly influenced (consciously or not) by a

\section{KEY POINTS}

- Disclosures of interests and appropriate management of conflicts of interest (COIs), when identified, are essential to producing high-quality, credible health guidelines.

- Through environmental scanning of the Canadian and international landscape and feedback from various stakeholders, we identified a need within the Canadian guideline community for leadership and advice on implementing best practices on COI.

- We have developed practical guidance and a toolkit to help guideline developers implement the Guidelines International Network principles on $\mathrm{COI}$, resulting in stronger policies on $\mathrm{COI}$ and protecting the scientific integrity of Canadian health guidelines.

secondary interest, such as the opportunity to derive personal benefit. ${ }^{11}$ Although COls can be financial, they can also be nonfinancial, arising from a competing professional, academic, personal or political role. Not all interests constitute a COI, and an assessment is needed to make this determination. ${ }^{23}$ Conflicts of interest can bias recommendations (e.g., overly strong or enthusiastic for a particular intervention) and ultimately be harmful to patients and the health system if biased recommendations are implemented. ${ }^{21}$ Guidelines for which COIs have not been appropriately managed may not be credible to stakeholders, in turn diminishing their impact or reducing confidence in the guideline endeavour. ${ }^{24}$

The involvement of individuals with content expertise is essential for enhancing the value of guideline recommendations. For example, content experts can provide unique insight into published research, help to identify relevant data or suggest clinically important nuances for interpreting the evidence. However, these individuals may have interests that could lead to COls. Therefore, guideline development requires striking a balance between the needs to inform the guidance by sufficient expertise and to minimize the impact of COls. Further, COls are not restricted to content experts: they may arise for anyone who participates in guideline development, including funders of guidelines, systematic review authors, guideline panel members, patients or their representatives, peer reviewers, and 
researchers who advance scholarship in guideline development methods, dissemination and implementation. Finally, COls can arise at any stage of guideline production, from topic selection to incorporating comments received during peer review. These considerations highlight the importance of a deliberate and thoughtful approach to avoiding and managing COIs in guideline development.

\section{What approaches have been developed for managing COIs in guideline development?}

\section{International approaches}

The World Health Organization, ${ }^{23}$ the National Institute for Health and Care Excellence, ${ }^{25}$ the United States Preventive Services Task Force $^{26}$ and the American College of Physicians ${ }^{27}$ have all recently updated their policies and procedures on COIs, including those for mitigating guideline-related COls. All policies define which financial and nonfinancial interests should be disclosed, describe the core elements of disclosure (such as whether both individuals and family members are covered), state the look-back period and specify how often disclosures are to be made. These organizations have also clarified how interests will be assessed and provided a range of options for the management of COIs (Table 1).23,25-27

Legislation in France requires all participants involved with healthrelated guideline development to make comprehensive declarations of interest and prohibits individuals with COls from participating in guideline-related activities. ${ }^{28}$ Individuals who do not disclose a relevant interest can be liable for up to 5 years' imprisonment and $€ 75000$ in fines. Further, decisions and advice from the Haute Autorite de Santé can be stricken or reversed by legal authorities if it is deemed that interests were not properly disclosed and managed. ${ }^{28}$

The International Committee of Medical Journal Editors (ICMJE) has also revised its guidance to authors about the importance of disclosing COls in scientific publications, specifying that "purposeful failure to disclose conflicts of interest is a form of scientific misconduct." ${ }^{29}$ Additionally, the ICMJE has proposed updates to its widely used disclosure form, improving clarity with respect to what financial and nonfinancial interests need to be reported, and clarifying that disclosed interests are not necessarily COIs. ${ }^{30}$ The committee also suggested mechanisms for reducing the workload associated with disclosure, such as online repositories like Convey, ${ }^{31}$ and encouraged "the development of other repositories as necessary to meet regional, linguistic and regulatory needs." ${ }^{30}$

Finally, in 2015, the GIN, a global network of guideline developers that aims to promote best practices in the development of high-quality guidelines, ${ }^{32}$ developed a set of 9 principles (Box 1 ) to provide guidance on how financial and nonfinancial COls should be both disclosed and managed, based on a review of the published literature and organizational policies. ${ }^{12}$

\section{Canadian developments}

The Institut national d'excellence en santé et en services sociaux (INESSS) in Quebec recently updated its COI policy, bringing it into alignment with the GIN principles and differentiating between interests and COIs, outlining how interests will be assessed for $\mathrm{COI}$ and how COls will be managed when identified. ${ }^{33}$ The Canadian Task Force on Preventive Health Care also recently reviewed its policies on COls to ensure consistency with GIN and has included an assessment of the specific actions taken in response. ${ }^{34}$

Shortly after the CIHR 2019 Best Brains Exchange ${ }^{35}$ meeting on COIs in guidelines, ${ }^{22,36}$ CMAJ announced a new approach to managing COIs, generally ${ }^{37}$ in response to the revised ICMJE guidance, and specifically in guidelines, ${ }^{38}$ indicating that all guidelines submitted to the journal from 2020 onward must adhere to the GIN principles to be eligible for publication. ${ }^{38}$

Groups that develop or fund guidelines, such as governments, nongovernmental organizations, specialty groups and others across Canada, will need to work together to support more consistent implementation of best practices. While gathering feedback from stakeholders (Appendix 1), we found that guideline developers requested leadership and advice on how to implement the GIN principles, and we aim to meet that need in this article.

\section{How can guideline developers overcome challenges that may arise when implementing the GIN principles?}

\section{Defining key terms}

Immediate tasks for each guideline developer will be to define key terms. For example, developers could define financial COls using thresholds that are more (e.g., any amount of financial relationship) or less (e.g., payments of $>\$ 10000$ ) stringent. Definitions of nonfinancial COls can encompass a wide range of secondary interests, and overly broad interpretation of such interests as conflicts could make nonfinancial COls "appear so pervasive that they cannot be avoided but only disclosed." 39,40 Guideline developers should therefore take care to identify factors that differentiate interests from COIs (such as if a reasonable person would consider the interest to unduly influence the individual's judgment as a member of the guideline pane $\left.{ }^{26}\right)$. Developers may also consider that overly inclusive lists of nonfinancial interests that constitute COIs could inappropriately burden, infringe on the privacy of, or lead to discrimination against those who must fill out disclosures. ${ }^{40}$ Developers seeking to implement the GIN principles may wish to consult other groups that have established definitions. ${ }^{12,20,21,23,25-27,28}$

\section{Guideline panel composition}

Once key terms have been defined, developers can operationalize and implement the GIN principles (expanded guidance can be found in Appendix 2, available at www.cmaj.ca/lookup/doi/10.1503/ cmaj.200651/tab-related-content, and a checklist for GIN principle implementation in Appendix 3 at www.cmaj.ca/lookup/doi/ 10.1503/cmaj.200651/tab-related-content). Principle 1 states that only "a minority" of panel members should have COls, without specifying a proportion. ${ }^{12}$ Developers may feel that a more restrictive threshold (i.e., closer to $0 \%$ ) will reduce the expertise of the panel, thereby compromising the value of the recommendations. However, if a less-stringent threshold is chosen (i.e., closer to 49\%), the panel may have too high a burden of conflict for the guideline to be credible. Developers should also consider that not all COIs are necessarily equal. For example, the presence of just 1 or 2 panellists with substantial financial COls could unduly compromise the credibility of the panel. 
Group

\begin{tabular}{|c|c|c|c|c|}
\hline Option "category" & $\begin{array}{l}\text { National Institute for Health } \\
\text { and Care Excellence }(2018)^{25}\end{array}$ & $\begin{array}{l}\text { United States Preventive } \\
\text { Services Task Force } \\
(2018)^{26}\end{array}$ & $\begin{array}{l}\text { Guidelines International } \\
\text { Network }(2015)^{12}\end{array}$ & $\begin{array}{c}\text { World Health } \\
\text { Organization }(2014)^{23}\end{array}$ \\
\hline $\begin{array}{l}\text { Full involvement } \\
\text { (disclosure only) }\end{array}$ & $\begin{array}{l}\text { No action other than the } \\
\text { process of open declaration } \\
\text { - the person can engage in all } \\
\text { aspects of the committee's } \\
\text { work. This is usually because } \\
\text { nothing is considered to } \\
\text { represent a perceived COI, but }\end{array}$ & $\begin{array}{l}\text { Information disclosure only. } \\
\text { Member may participate as } \\
\text { primary lead, }{ }^{\star} \text { and discuss } \\
\text { and vote on the topic. }\end{array}$ & Not applicable & $\begin{array}{l}\text { No action required } \\
\text { beyond declaration at the } \\
\text { guideline development } \\
\text { group meeting and } \\
\text { reporting in the published } \\
\text { guideline. }\end{array}$ \\
\hline
\end{tabular}

Limited involvement The person can engage in committee discussion or provide advice (for example, because of their expert knowledge), but is excluded from developing recommendations and decision-making on the matter relating to their declared interest. Involvement may be limited to answering questions from the committee.
No involvement (complete exclusion)
The person can have no input to a specific topic, either from the start (nonappointment) or for part of the committee's work relating to that topic. It may be appropriate in these cases to withhold any confidential meeting papers for that item, especially when the person could benefit from the information.
- Member may not participate as the primary lead of the topic specific to the conflict, but may serve as a nonprimary lead ${ }^{*}$ on the topic workgroup and discuss and vote on the topic.

- Member may not participate as the primary spokesperson for the topic specific to the conflict, but may serve as a nonprimary lead on the topic workgroup and discuss and vote on the topic.

- Member may not participate as a lead in the topic workgroup specific to conflict, but may discuss and vote on the topic.

Member may not participate as a lead on the topic workgroup specific to the conflict, or discuss or vote on the topic. Member will leave the meeting room for all discussion and voting. Member's recusal will be denoted in the publicly released recommendations.
- Panel members with any form of COI cannot be chairs of the working group.

- A co-chair with no COIs can be appointed if a chair with $\mathrm{COI}$ is unavoidable.

- Panel members with a relevant financial COI should not be involved in deciding about the direction or strength of a recommendation. These members should not participate in this phase of guideline development and should be physically absent from the discussion about the direction and strength of the recommendation.

Not applicable
- The individual with the conflict may be excluded from the formulation of specific recommendations but allowed to participate in all discussions.

- The individual with the conflict may be barred from participating in discussions as well as in the formulation of the recommendations. They can be asked to leave the meeting during the development and ratification of any recommendations related to their $\mathrm{COI}$.

No participation is allowed - the COI is deemed serious enough to preclude membership in the guideline development group or participation as a contractor for the World Health Organization in a specific guideline development process.

Note: $\mathrm{COI}=$ conflict of interest.

* "Each topic team (see US Preventive Services Task Force Procedure Manual Section 1.9) includes the Agency for Healthcare Research and Quality Medical Officer, a Task Force chair or co-vice chair, representatives from the evidence-based practice center conducting the systematic evidence review, and several Task Force members, known as 'leads.' One of the Task Force leads serves as the primary lead for that topic."

We suggest that the allowable threshold for panel members with COls should be developed on a group-by-group basis, considering their thresholds for different forms of $\mathrm{COI}$ in the context of their panel's mandate, as well as the following points. First, GIN principle
7 suggests that expert input can be obtained from individuals who are not members of the panel, such as expert advisers. In such cases, the guideline panel could be composed primarily of panellists without COls who seek input from these advisers to inform 
Box 1: Guidelines International Network: principles for disclosure of interests and management of conflicts in guidelines $^{12}$

- Principle 1: Guideline developers should make all possible efforts to not include members with direct financial or relevant indirect conflicts of interests (COIs).

- Principle 2: The definition of $\mathrm{COI}$ and its management applies to all members of a guideline development group, regardless of the discipline or stakeholders they represent, and this should be determined before a panel is constituted.

- Principle 3: A guideline development group should use standardized forms for disclosure of interests.

- Principle 4: A guideline development group should disclose interests publicly, including all direct financial and indirect COIs, and these should be easily accessible for users of the guideline.

- Principle 5: All members of a guideline development group should declare and update any changes in interests at each meeting of the group and at regular intervals (for example, annually for standing guideline development groups).

- Principle 6: Chairs of guideline development groups should have no direct financial or relevant indirect COIs. When direct or indirect COIs of a chair are unavoidable, a co-chair with no COIs who leads the guideline panel should be appointed.

- Principle 7: Experts with relevant COIs and specific knowledge or expertise may be permitted to participate in discussion of individual topics, but there should be an appropriate balance of opinion among those sought to provide input.

- Principle 8: No member of the guideline development group deciding about the direction or strength of a recommendation should have a direct financial $\mathrm{COI}$

- Principle 9: An oversight committee should be responsible for developing and implementing rules related to COIs.

From Annals of Internal Medicine, Schünemann HJ, Al-Ansary, LA, Forland F, et al Guidelines International Network: Principles for disclosure of interests and management of conflicts in guidelines, 163(7), 548-53. Copyright (C 2015 American College of Physicians. All Rights Reserved. Reprinted with the permission of American College of Physicians, Inc.

their judgments about the relative benefits and harms of an intervention. ${ }^{41,42}$ By analogy, a judge ruling on a case of breach of contract for construction services does not need to be an expert in construction standards. Rather, the judge is an expert in jurisprudence who weighs the evidence from both parties, together with input from content experts (e.g., engineers).

Second, to find panellists without COls, developers might consider broadening their search beyond their usual pool of candidates to include those at earlier career stages, from other clinical areas or even from other disciplines, provided that they have the requisite skills for guideline development; this will also increase the diversity of perspectives in the process. Third, panels may also obtain expert input through consultations, peer review or other external review processes - although disclosures of interests should be completed by all reviewers for panels to consider when interpreting comments.

Fourth, organizations should develop clear policies for how COls will be managed, so that rules for participating are clear to prospective panellists. The knowledge that receiving financial benefits from an entity may preclude future participation in a guideline panel (see principles 6 and 8 ) will place the responsibility of accepting such benefits on the prospective panellist. Fifth, once policies are finalized, developers will need to consider the anticipated total number of recusals for discussions on any given topic when selecting panel members. As this can be challenging, an approach that recruits panellists without COIs is preferable.

\section{Establishing procedures}

Principle 6 states that the panel chairs must be free of COls. ${ }^{12}$ Principles 7 and 8 indicate that experts and panellists with COls may be permitted to participate in panel discussions, but that members with financial COls should be physically absent from discussions "about the direction and strength of the recommendation." 12 Managing the restrictions of principle 8 will require strong leadership from panel chairs, along with explicit policies to guide how input is sought and incorporated. For example, groups should determine and describe in advance the potential management options when a COI is identified, enabling transparency and consistency in application. . $^{23,25-27}$

\section{Transparency}

Public disclosure of COls, regular updating of $\mathrm{COI}$ information and declaration of interests by panellists are addressed by principles 3, 4 and $5 .{ }^{12}$ Implementation of these principles will require the availability of suitable forms for recording secondary interests and decisions regarding COls and a platform for making this information publicly accessible. Groups should also consider whether they will verify COI declarations, and how they will deal with inaccurate declarations. The online toolkit (https://wiki.gccollab.ca/PHAC_Conflict_of_Interest _Toolkit_for_Guideline_Development) includes sample forms for collecting COls. Groups may also consider using or adapting the updated ICMJE forms, or online repositories, as appropriate. ${ }^{30}$

\section{Oversight committee}

Principle 9 specifies that guideline developers should strike an oversight committee to develop, manage and implement COI policies, including much of the work described above. ${ }^{12}$ Oversight committees may be asked to make decisions about how to deal with unique $\mathrm{CO}$ situations of various panellists and experts. As with guideline development itself, these decisions will require judgment, which can be facilitated by transparent rules and procedures for identifying and managing COIs.

Although the GIN principles do not explicitly say so, members of oversight committees should be free of $\mathrm{COI}$, and these committees may include independent members drawn from outside the guideline developer's organization. When an organization developing a guideline depends on industry funding and produces guidelines related to products from industry partners, the oversight committee would ideally be extra-organizational. ${ }^{43}$

\section{What tools are available to assist Canadian guideline developers?}

At the Best Brains Exchange, participants highlighted the need for national leadership to help Canadian developers improve the disclosure and management of COls in guidelines. Accordingly, as mentioned earlier, the Public Health Agency of Canada's Guidance Innovation Hub offers an online toolkit (https://wiki.gccollab.ca/ PHAC_Conflict_of_Interest_Toolkit_for_Guideline_Development) 
to assist internal and external developers of guidelines in implementing the GIN principles and other best practices for disclosing and managing COIs. In addition to providing sample COI forms, the toolkit highlights resources from various groups that describe how hypothetical financial and nonfinancial COls might be handled by developers, including a discussion of factors that might be considered when making these judgments.

\section{What important issues have not been addressed by the GIN principles?}

Although the GIN principles are an important framework for assessing and managing COIs, they are not exhaustive, and additional challenges remain. The GIN principles do not require sponsoring or funding organizations to disclose their interests and do not address other institutional conflicts of interest, such as funding from industry to universities, but the principles suggest that public and standardized disclosure forms are used that should include such funding, if known. ${ }^{44}$ Because industry funding is common among Canadian guideline producers, more work will be required on how to ensure that these COls are appropriately disclosed and managed. ${ }^{43,45}$ Patient involvement in guidelines, particularly if patient partners receive funding to advocate for their condition, must also be considered. In addition to the potential future expansion of the GIN principles, journal editorial requirements and tools for evaluating guidelines ${ }^{46-48}$ could both play a role in addressing these gaps. For example, one new tool obtains information directly from guideline group members on whether COls were managed appropriately during development. ${ }^{48}$

\section{Conclusion}

Conflicts of interest represent a potential threat to the trustworthiness, credibility and utility of guidelines produced in Canada and abroad. The GIN principles represent a rigorous approach to identifying and managing such interests. Although implementation may pose challenges, international and domestic examples suggest that this goal is feasible. Implementing the GIN principles will help to protect the integrity, scientific rigour, transparency and accountability of Canadian guidance.

\section{References}

1. Johnson L, Stricker RB. Attorney General forces Infectious Diseases Society of America to redo Lyme guidelines due to flawed development process. $J$ Med Ethics 2009;35:283-8.

2. Lenzer J. French guidelines are withdrawn after court finds potential bias among authors. BMJ 2011;342:d4007.

3. Howlett K. Conflicts of interest didn't influence new opioid standards: review. Globe and Mail [Toronto] 2017 Sept. 7. Available: www.theglobeandmail.com/ news/national/conflicts-of-interest-didnt-influence-new-opioid-standards-review/ article36199835/ (accessed 2019 Oct. 23).

4. Dyer O. WHO drops opioid guidelines after criticism of corporate influence. BMJ 2019;365:14374.

5. Cosgrove L, Bursztajn HJ, Erlich DR, et al. Conflicts of interest and the quality of recommendations in clinical guidelines. J Eval Clin Pract 2013;19:674-81.

6. The Canadian Press. Co-author of controversial meat study did not disclose ties to 'classic front group'. National Post [Toronto] 2019 Oct. 5. Available: https://nationalpost.com/news/canada/scientist-responds-to-critique-of-industry -ties-after-publishing-study-on-red-meat (accessed 2019 Oct. 23).
7. Cohen D, Brown E. Surgeons withdraw support for heart disease advice. British Broadcasting Corporation 2019 Dec. 9. Available: www.bbc.com/news/ health-50715156 (accessed 2020 Jan. 16).

8. Connolly A. Canadians can now see conflicts of interest declared by COVID-19 vaccine task force. Global News 2020 Sept. 22. Available: https://globalnews.ca/news /7351016/covid-19-vaccine-task-force-conflicts-of-interest-disclosures/ (accessed 2020 Oct. 21).

9. Lexchin J, Mintzes B, Bero L, et al. Canada's COVID-19 Vaccine Task Force needs better transparency about potential conflicts of interest. The Conversation 2020 Oct. 8. Available: https://theconversation.com/canadas-covid-19 -vaccine-task-force-needs-better-transparency-about-potential-conflicts-of -interest-147323 (accessed 2020 Oct. 21).

10. Brouwers MC, Kho ME, Browman GP, et al.; AGREE Next Steps Consortium. AGREE II: advancing guideline development, reporting and evaluation in healthcare. CMAJ 2010;182:E839-42.

11. Institute of Medicine (US) Committee to Advise the Public Health Service on Clinical Practice Guidelines. Clinical practice guidelines: directions for a new program. In: Field MJ, Lohr KN, editors. Washington (DC): National Academies Press (US); 1990. Available: www.ncbi.nlm.nih.gov/books/NBK235751/ (accessed 2019 July 10).

12. Schünemann HJ, Al-Ansary LA, Forland F, et al.; Board of Trustees of the Guidelines International Network. Guidelines International Network: principles for disclosure of interests and management of conflicts in guidelines. Ann Intern Med 2015;163:548-53.

13. Guyatt G, Akl EA, Hirsh J, et al. The vexing problem of guidelines and conflict of interest: a potential solution. Ann Intern Med 2010;152:738-41.

14. Siemieniuk RA, Agoritsas T, Macdonald H, et al. Introduction to BMJ rapid recommendations. BMJ 2016;354:i5191.

15. Schünemann HJ, Osborne M, Moss J, et al.; ATS Ethics and Conflict of Interest Committee and the Documents Development and Implementation Committee. An official American Thoracic Society Policy statement: managing conflict of interest in professional societies. Am J Respir Crit Care Med 2009;180:564-80.

16. Boyd EA, Bero LA. Improving the use of research evidence in guideline development: 4. Managing conflicts of interests. Health Res Policy Syst 2006;4:16.

17. Boyd EA, Akl EA, Baumann M, et al.; ATS/ERS Ad Hoc Committee on Integrating and Coordinating Efforts in COPD Guideline Development. Guideline funding and conflicts of interest: article 4 in Integrating and coordinating efforts in COPD guideline development. An official ATS/ERS workshop report. Proc Am Thorac Soc 2012;9:234-42.

18. Schünemann HJ, Lerda D, Dimitrova N, et al.; European Commission Initiative on Breast Cancer Contributor Group. Methods for development of the European Commission Initiative on Breast Cancer guidelines: recommendations in the era of guideline transparency. Ann Intern Med 2019;171:273-80.

19. Col Policy for Cochrane Library Content (2020). London (UK): Cochrane; 2020. Available: https://training.cochrane.org/online-learning/editorial-policies/coi -policy/coi-policy-cochrane-library (accessed 2020 Sept. 21).

20. Morciano C, Basevi V, Faralli C, et al. Policies on conflicts of interest in health care guideline development: a cross-sectional analysis. PLoS One 2016;11:e0166485.

21. Norris SL, Holmer HK, Ogden LA, et al. Conflict of interest in clinical practice guideline development: a systematic review. PLoS One 2011;6:e25153.

22. CIHR/PHAC Best Brains Exchange. Reducing and managing conflicts of interest in clinical practice guideline development: Do we need Pan-Canadian standards? GCwiki; 2019. Available: https://wiki.gccollab.ca/images/0/0b/BBE_ COI_in_CPG_development_EN_FINAL.pdf (accessed 2019 Oct. 14).

23. 6. Declaration and management of interest. In: WHO Handbook for Guideline Development. 2nd ed. Geneva: World Health Organization; 2014. Available: https://apps.who.int/iris/bitstream/handle/10665/145714/9789241548960_eng .pdf (accessed 2019 Nov. 26).

24. Shaneyfelt TM, Centor RM. Reassessment of clinical practice guidelines: go gently into that good night. JAMA 2009;301:868-9.

25. Policy on declaring and managing interests for NICE advisory committees. London (UK): National Institute for Health and Care Excellence (NICE); 2019. Available: www.nice.org.uk/Media/Default/About/Who-we-are/Policies-and -procedures/declaration-of-interests-policy.pdf (accessed 2019 Nov. 26).

26. Ngo-Metzger Q, Moyer V, Grossman D, et al. Conflicts of interest in clinical guidelines: update of U.S. Preventive Services Task Force policies and procedures. Am J Prev Med 2018;54(Suppl 1):S70-80.

27. Qaseem A, Wilt TJ; Clinical Guidelines Committee of the American College of Phys icians. Disclosure of interests and management of conflicts of interest in clinical guidelines and guidance statements: methods from the Clinical Guidelines Committee of the American College of Physicians. Ann Intern Med 2019;171:354-61.

28. Guide des déclarations d'intérêts et de gestion des conflits d'intérêts. Saint-Denis (France): Haute Autorité de Santé; 2013, modified 2017 Mar. 15. Available: www. has-sante.fr/upload/docs/application/pdf/guide_dpi.pdf (accessed 2019 July 10). 
29. Recommendations for the conduct, reporting, editing, and publication of scholarly work in medical journals. International Committee of Medical Journal Editors; updated 2018. Available: www.icmje.org/news-and-editorials/ icmje-recommendations_annotated_dec18.pdf (accessed 2019 Nov. 26).

30. Taichman DB, Backus J, Baethge $C$, et al. A disclosure form for work submitted to medical journals: a proposal from the International Committee of Medical Journal Editors. JAMA 2020;323:1050-1.

31. Convey Global Disclosure System. Washington (DC): Association of American Medical Colleges. Available: www.aamc.org/services/convey (accessed 2020 Mar. 27).

32. Back to our roots: annual report 2019. Scottish Charity no SC 034047. Guidelines International Network. Available: https://g-i-n.net/document-store/ annual-reports/agm-2019/annual-report-2019 (accessed 2020 Mar. 27).

33. Politique de prévention, d'identification, d'évaluation et de gestion des conflits d'intérêts et de rôles des collaborateurs de l'INESSS Institut national d'excellence en santé et en services sociaux (INESSS) March 2020. Available: www.inesss.qc.ca/ fileadmin/doc/INESSS/DocuAdmin/Lois_Politiques/Politique_INESSS_Conflit_ interets_Collaborateurs_2020.pdf (accessed 2020 Nov. 6).

34. Policy on disclosures of interests and management of conflicts of interest. Canadian Task Force on Preventive Health Care; 2020. Available: https://canadiantaskforce. ca/about/conflict-of-interest-policy/ (accessed 2020 Oct. 7)

35. Exchanges BB. Ottawa: Canadian Institutes of Health Research; modified 2020 Aug. 12. Available: https://cihr-irsc.gc.ca/e/43978.html (accessed 2020 Oct. 7).

36. Canadian Institutes of Health Research (ClHR); Public Health Agency of Canada. Reducing and managing conflicts of interest in clinical practice guideline development: Do we need Pan-Canadian standards? Ottawa: CIHR; modified 2019 May 10. Available: www.cihr-irsc.gc.ca/e/51455.html (accessed 2019 Nov. 26).

37. Kelsall D. Updated CMAJ policy on undisclosed competing interests. CMAJ 2019;191:E116-7.
38. Kelsall D. New CMAJ policy on competing interests in guidelines. CMAJ 2019;191:E350-1.

39. Grundy Q, Mayes C, Holloway K, et al. Conflicts of interest as ethical shorthand: understanding the range and nature of "non-financial conflict of interest" in biomedicine. J Clin Epidemiol 2020;120:1-7.

40. Bero LA, Grundy Q. Why having a (nonfinancial) interest is not a conflict of interest. PLoS Biol 2016;14:e2001221.

41. Jatoi I, Sah S. Clinical practice guidelines and the overuse of health care services: need for reform. CMAJ 2019;191:E297-8.

42. Ioannidis JPA. Professional societies should abstain from authorship of guidelines and disease definition statements. Circ Cardiovasc Qual Outcomes 2018;11:e004889.

43. Elder K, Turner KA, Cosgrove L, et al. Reporting of organizational financial conflicts of interest by producers of Canadian clinical practice guidelines: a descriptive study. CMAJ 2020;192:E617-25.

44. Lexchin J. New CMAJ policy on competing interests in guidelines needs strengthening. CMAJ 2019;191:E870.

45. Grant K. The pressure of Big Pharma. Globe and Mail [Toronto] 2017 June 19 Available: www.theglobeandmail.com/news/national/the-pressure-of-big -pharma-financial-conflicts-of-interest-common-on-medical-guidelinepanels/ article35389639/ (accessed 2020 Jan. 31)

46. AGREE Next Steps Consortium. The AGREE II Instrument. Appraisal of Guidelines for Research \& Evaluation; 2017. Available: www.agreetrust.org/wp-content/ uploads/2017/12/AGREE-II-Users-Manual-and-23-item-Instrument-2009-Update -2017.pdf (accessed 2020 Sept. 21).

47. Shaughnessy AF, Vaswani A, Andrews BK, et al. Developing a clinician friendly tool to identify useful clinical practice guidelines: G-TRUST. Ann Fam Med 2017;15:413-8.

48. Wiercioch W, Akl EA, Santesso N, et al.; PANELVIEW Working Group. Assessing the process and outcome of the development of practice guidelines and recommendations: PANELVIEW instrument development. CMAJ 2020;192:E1138-45.
Competing interests: Diane Kelsall was the interim editor-in-chief of CMAJ until October 2019, and is currently editor for CMAJ Open and consulting editor for CMAJ. Gillian Leng is an executive director of the National Institute for Health and Care Excellence, which also has a policy on declaring and managing conflicts of interest, and is the chair of the Guidelines International Network, which provides advice on managing potential conflicts of interest. Brett Thombs, Ainsley Moore and Navindra Persaud are, respectively, chair, vice-chair and a member of the Canadian Task Force on Preventive Healthcare, which develops clinical practice guidelines and also has a policy on declaring and managing conflicts of interests. Navindra Persaud reports receiving research funding from the Canadian Institutes of Health Research, the Ontario SPOR Support Unit, and the Canada Research Chairs program, outside of the submitted work. Holger Schünemann is a member of the GRADE working group and was the lead author on the Guidelines International Network principles for disclosure of interests, and is the corresponding author on the manuscript describing the PANELVIEW instrument. Rachel Rodin and Marcello Tonelli report receiving funding from the Canadian Institutes of Health Research to host the Best Brains Exchange referred to in the article. Elie Akl reports contributing to a number of studies on conflicts of interest. G. Michael Allan reports being an author of guidelines, who has received travel support, honoraria for speaking at conferences, and research support. The supports have been from nonprofit sources. Dr. Allan has received no funding from the pharmaceutical industry. Isabelle Ganache reports receiving personal fees from Institut national d'excellence santé et en services sociaux (INESSS), as director of the Bureau - Methodologies and Ethics (which is responsible for the institutional policy on declaring and managing conflicts of interest), during the conduct of the study. Quinn Grundy reports receiving grants from the Social Science and Humanities Research Council and a Connaught New Research Award from the University of Toronto, outside of the submitted work. No other competing interests were declared.

This article has been peer reviewed.

Affiliations: Centre for Communicable Diseases and Infection Control (Traversy, Rodin), Public Health Agency of Canada, Ottawa, Ont.; Department of Medicine, University of Calgary (Barnieh, Tonelli), Calgary, Alta.; Department of Internal Medicine (Akl), American University of Beirut, Beirut, Lebanon; Department of Family Medicine (Allan), University of Alberta,
Edmonton, Alta.; School of Epidemiology and Public Health (Brouwers), University of Ottawa, Ottawa, Ont.; Institut national d'excellence en santé et en services sociaux (Ganache), Montréal, Que.; Lawrence S. Bloomberg Faculty of Nursing (Grundy), University of Toronto, Toronto, Ont.; Department of Health Research Methods, Evidence and Impact (Guyatt, Schünemann), McMaster University Faculty of Health Sciences, Hamilton, Ont.; CMAJ (Kelsall), Ottawa, Ont.; National Institute for Health and Care Excellence (NICE) (Leng), London, UK; Department of Family Medicine (Moore), McMaster University, Hamilton, Ont.; Department of Family and Community Medicine (Persaud) and Li Ka Shing Knowledge Institute (Straus), St. Michael's Hospital, Toronto, Ont.; Lady Davis Institute and Department of Psychiatry (Thombs), Jewish General Hospital and McGill University, Montréal, Que.; Institut für Evidence in Medicine (Schünemann), Medical Center \& Faculty of Medicine, University of Freiburg, Freiburg, Germany

Contributors: Gregory Traversy, Lianne Barnieh, Rachel Rodin and Marcello Tonelli contributed to the conception and design of the work and writing of the initial draft, as well as reviewing and editing of subsequent drafts. Elie Akl, G. Michael Allan, Melissa Brouwers, Isabelle Ganache, Gordon Guyatt, Quinn Grundy, Diane Kelsall, Gillian Leng, Ainsley Moore, Navindra Persaud, Holger Schünemann, Sharon Straus and Brett Thombs contributed to writing the initial draft, and reviewed and edited subsequent drafts. All of the authors participated in the planning and design of the Best Brains Exchange referred to within the manuscript. All of the authors revised the manuscript critically for important intellectual content, gave final approval of the version to be published and agreed to be accountable for all aspects of the work.

Funding: No funding was received for the development of this manuscript.

Content licence: This is an Open Access article distributed in accordance with the terms of the Creative Commons Attribution (CC BY-NC-ND 4.0) licence, which permits use, distribution and reproduction in any medium, provided that the original publication is properly cited, the use is noncommercial (i.e., research or educational use), and no modifications or adaptations are made. See: https://creativecommons.org/licenses/by-nc-nd/4.0/

Disclaimer: Diane Kelsall is a consulting editor, and Navindra Persaud is an associate editor, for CMAJ and were not involved in the editorial decision-making process for this article.

Correspondence to: Gregory Traversy, gregory.traversy@canada.ca 